\title{
La Gran Pizarra, la ciudad de la imagen ${ }^{\star}$
}

*Este trabalho foi ilustrado com obras plásticas do autor.

Nicolás Amoroso BoelcKe

Universidad Autonoma Metropolitana - Azcapotzalco/México 


\section{Resumen}

El articulo propone una lectura de la ciudad como imagen, partiendo desde una fotografía hipotética. Aborda, primero, el sentido de la imaginación y los límites para compartirla. Luego, tomando la imagen de referencia, construye disímiles lecturas a través de un diálogo entre dos observadores del objeto. Al intervenir el autor de la imagen aparece una dimensión que no había sido contemplada. Deja así entrever la diversidad de lecturas que un mismo texto icónico produce, pues la ciudad es el gran pizarrón donde se escribe la historia y, tomando una metáfora escénica, presenta, sin agotarlas, las diversas cotas de lectura a las que se tiene acceso para identificar sus componentes.

\section{Palabras-clave}

lectura, ciudad, imagen, iconismo, polisemia

\section{Abstract}

This article proposes a reading of the city as image, from a hypothetical photography. It approaches, firstly, the sense of imagination and the limits to share it. Then, taking the reference image, it builds different readings through a dialogue between both of the observers of the object. With the interference of the image's author, a dimension not yet contemplated appears. Consequently, it allows to glimpse the diversity of the readings that a same iconic text can produce. The city is the great blackboard in which the history is written and, taking a scenic metaphor, presents, without exhausting, the different parts of the reading to which someone has access in order to identify its components.

\section{Key words}

reading, city, image, iconism, polissemy 
i yo imagino que tú imaginas no quiere decir que los dos - estemos imaginando lo mismo. ¿Quién me dice que la mía contiene a la tuya?, tal vez tú; pero aun en ese caso, ¿hasta que punto puedo absorber todas las sutilezas de tu imaginario? No puedo, por más que tenga el ferviente deseo de lograrlo.

Además, está el problema de la interpretación, donde imagino cosas que tienen que ver con lo que creo conocerte. Pero, todos sabemos que por más que lo anhele, no te conozco, no te conozco lo suficiente y esta es la fascinación que en mí ejerce, creer que llegaré a conocerte antes de que la muerte nos alcance. Vano propósito que llena los humos de nuestras vidas: seguir imaginando juntos, cada quien por su lado, donde ni siquiera la complementariedad alcanzaremos.

\section{La imagen, signo de las cosas}

Tal vez aquí podamos acercarnos un poquito en nuestras dimensiones individuales. Aproximar tú quimera y la mía por medio de la imagen, como representación de lo existente. Es una similitud, un signo de las cosas que puede conservarse independientemente de las cosas mismas (Abbagnano, 1999, p. 651). Tanto, y mejor aún, cuando tú y yo podemos verla en el mismo momento, juntos. La fotografía está allí, es un texto, nos habla en forma elocuente: ${ }^{1}$ estamos mirando una calle. Observa, me dice ella, y señala un puesto de periódicos, es grande y está colmado de publicaciones de diverso tipo. La imagen muestra un verdadero universo de imágenes en las revis-

1. A partir de una voluntad puramente documental, el film penetra poco a poco en el terreno del relato, de la historia, que no por ser real deja de adoptar las formas de la ficción (Ropars Wuilleumier, 1971, p. 31). 
tas que no podremos hojear, pero desde las portadas nos convencen de su existencia por el propio objeto que representan. La imagen verdadera y propia es lo impreso, formado y diferenciado del objeto existente conforme a su existencia y que, por lo tanto, no sería si el objeto mismo no existiera (Abbagnano, 1999). Ella sigue concentra-

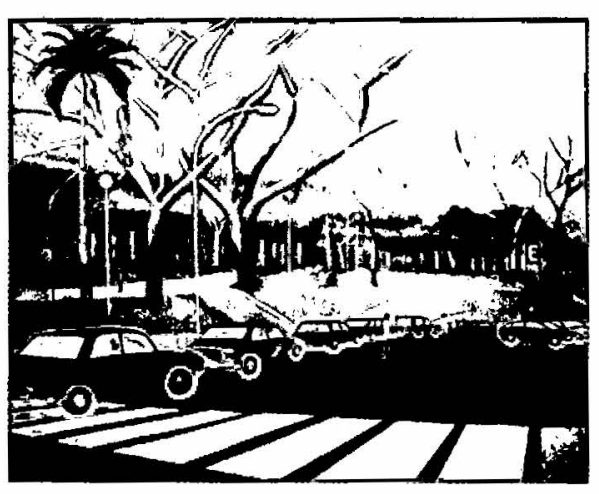
da en el puesto, en las publicaciones, y es así que destaca: eso indica que es un pueblo culto, que lee. Pienso en el gran porcentaje de analfabetos que arrojan las estadísticas y que ella desconoce por no pertenecer al país. Acerca una lupa para observar mejor y agrega que hay revistas caras y hasta especializadas, se ve muy claramente, incorpora ella, que es gente interesada en cuestiones diversas y trascendentes. Sucede, sin embargo, que muy pocos tienen acceso a ese material. Fíjate, agrega entusiasta, los periódicos muestran en sus titulares que responden a un amplio abanico político, esto indica que existe libertad dada la índole heterogénea de lo que exhiben. En esto se acerca bastante a lo real, si aceptamos primero que el conjunto está dentro de un registro de lo permitido, ya que el crecimiento de alternativas políticas más radicales ha sido coartado por la inteligencia del estado aunado a una serie de frustraciones de la causa popular. Si la imagen es un texto que podemos leer, en estos titulares, la palabra es la imagen que nos informa sobre un conjunto híbrido. La palabra como significado último o primero de un acto de comunicación. El discurso tiene el sentido de la realidad posible que manifiesta y, contrariamente, oculta la verdad que no puede exponerse. Además, enfatiza ella, el entorno es el de un barrio de pocos recursos y ello habla de que los sectores más desprotegidos tienen un interés elevado. Conozco el sitio donde fue tomada la placa y por su angulación, miente o, quizá, el autor buscó enfatizar un contraste entre lo paupérrimo del medio y la exhuberancia de las publicaciones. Lo cierto es que se encuentra en 
el límite entre dos asentamientos de clases distintas. La de mayor poder adquisitivo está a las espaldas del fotógrafo.

Una imagen significa a partir de lo que muestra. Para el que tomó la foto, el puesto de periódicos podría haber sido una simple referencia que entró en el encuadre, o se encuentra allí porque no lo pudo evitar, dado que su interés primordial se ubicaba en otro punto: un carromato tirado por caballo que traslada trastos viejos está cruzando la escena. Quería, tal vez, mostrar un pasado que se niega a desaparecer. Esa es mi interpretación de su intención, aunque es altamente probable que él viese otra cosa que yo no percibo y la imagen tiene para mí un significado distinto del que le dio origen. En tanto ella, realiza una lectura diversa, válida, a partir de los elementos que destaca, si no fuese porque ignora el entorno y la realidad en la que se inscribe y por ello, me parece, sus conjeturas están equivocadas. Le aporto esos datos que le faltan, pero no está muy convencida de mis aseveraciones. Es innegable que es mejor lo que ella percibe porque, en definitiva, es el futuro que anhelamos. Una ficción que nos encanta y tranquiliza frente a una realidad decididamente más cruda.

Conozco al fotógrafo y lo llamo poniéndola al teléfono. Confirma mis datos sociológicos pero contradice mi interpretación sobre el propósito de la imagen. Su intención fue retratar una atmósfera, con ese tamiz tan particular que la lluvia ${ }^{2}$ fina le confiere al paisaje urbano.

La imagen está cargada de significados, que son diversos, de acuerdo al ángulo desde el que se los observe. Todas y cada una de las interpretaciones son factibles, algunas están contenidas en la propuesta ${ }^{3}$, para otras es necesario contextualizarla en la realidad de la que emerge.

¿Por qué no pensar que el fotógrafo tenía in mente una imagen borgeana al momento de componer la suya?, una imagen que

2. Lo húmedo y lo seco tienen su influencia hasta en la literatura. El poeta inglés Tenneyson mostró su predilección por palabras como tenue, pálido, débil, borroso, nublado, oscuro, frío, monótono, mustio, empapado, calado, rociado, etc., etc. Asi, la humedad del paisaje en que vivió Tennyson se refiejó en su lenguaje (Beljon, 1993, p. 100).

3. El antiguo estilo de interpretación era insistente, pero respetuoso; sobre el significado literal, erigía otro significado. El moderno estilo de interpretación excava y, en la medida que excava, destruye; escarba 'más allá del texto' para descubrir un subtexto que resulte ser el verdadero (Sontag, 1996, p. 29). 
deriva de otra y permite ver una circunstancia que de distinta manera, tal vez, le hubiera pasado desapercibida.

\section{Los carros de costado sentencioso}

franqueaban tu mañana

$y$ eran en las esquinas tiernos los almacenes

como esperando un ángel (Carrizo, 1983, p. 192).

Ahora, condicionado por esta inesperada asociación, trato de recordar, primero; como no lo consigo, tomo la lupa para ver si en una literalidad, no siempre adecuada, podía encontrar la ternura de los negocios barriales. Inevitablemente está allí, no el que se refiere a la tienda de comestibles, lo reemplaza un bazar que hasta puede contener un ángel... de porcelana, o latón. Es posible que el fotógrafo conociese el poema y en un encuentro fortuito con la realidad hubiese podido registrar el carromato de costado sentencioso o soy yo en mi doble lectura que creo el vínculo, pienso que si fuese editor que necesita ilustrar el poema de Borges utilizaría esa imagen (cortándole el puesto de revistas). Creo que una y otra terminan encontrándose en algún punto pese a que no se refieren ni al exacto momento histórico, ni a la misma hora del día y, sin embargo, se corresponden.

La imagen, en tal caso, antecede a la imagen que estamos detallando, ya estaba, tenía una existencia previa a su propia presencia gráfica. Esto en la inteligencia de quien lo percibe como un enlace, es por lo tanto una interpretación. La imagen, entonces, es un fenómeno que puede estar contenida en un antecedente, en el propio medio o en otro diferente, es anticipatoria. También puede constituir una prefiguración que no termina de cuajar o un algo que luego encontrará su sentido. La imagen como forma de la imaginación.

La primera imagen siempre volvía: la habitación roja con las mujeres vestidas de blanco. A menudo algunas imágenes vuelven a mi mente con tozudez sin que sepa lo que quieren de mí. Después desaparecen y reaparecen de nuevo, y son exactamente iguales. Cuatro mujeres vestidas de blanco en una habitación roja. Se movian y 
se hablaban al oído, y eran extremadamente misteriosas. Justo entonces yo estaba ocupado en otras cosas pero, como volvían con tanta tenacidad, comprendi que querían algo. La escena que acabo de describir me ha perseguido un año entero. Al principio, naturalmente, no sabía cómo se llamaban las mujeres, ni por qué se movian bajo una luz matinal gris en una habitación empapelada en rojo. Había rechazado esta imagen una y otra vez y me había negado a colocarla como base de una película (o de lo que sea). Pero la imagen se ha obstinado y, de mala gana, la he identificado: tres mujeres que esperan a que muera la cuarta. Se turnan para velarla (Bergman, 1992, p. 74).

Aquí la imagen actúa como anticipación de lo existente pero, no por ello pierde el sentido de representación de una cosa dada, real, verdadera: cuatro mujeres en un ámbito determinado. En cierto sentido los términos imagen y representación tienen el mismo significado (Ferrater Mora, 1998, p. 211). Falta la interpretación que le confiera su carácter para que la imagen adquiera un motivo, la narración ${ }^{4}$ que le permita su ser temporal a esa presencia espacial. Finalmente Ingmar Bergman le encontrará una dirección a esas presencias recurrentes y de allí surgirá el guión y la película titulada Gritos y susurros.

La propia ciudad que la fotografía representa puede constituirse en un hecho que la precede. Tanto por las posibilidades de manipulación que el medio facilita como por la constitución de un suceso que el autor supo ver como un instante único e irrepetible, inclusive para él mismo. El fotógrafo narraba que su intención fue la de retratar un clima, un sentimiento que la luz y la lluvia le produjeron. Esa lluvia omnipresente en este retrato de barrio convoca a otros fantasmas. La lectura de una imagen que se ha instalado en mi espíritu, motiva entonces otros recuerdos y asociaciones. A mitad de la cuadra, casi escondido por la angulación y un puesto de verduras se abre una callejuela estrecha cuyo estado seguramente ha sido alterado por la llovizna.

4. ...la dimensión narrativa que es fundamental en semiótica (Greimas; Courtés, 1991, p. 137). 
Tal vez allá en la infancia, su voz de alondra tomó ese tono oscuro de callejón (...) tus tangos son criaturas abandonadas que cruzan sobre el barro del callejón cuando todas las puertas están cerradas y ladran los fantasmas de la canción. 309

Es el conocimiento de lo que no se ve que me lleva en este caso a establecer la analogía. Ejercer una vieja preocupación mía, la de ver lo que está detrás, la imagen que la propia imagen oculta. Tal presunción es un elemento de tensión que carga de energía la imagen que se trate, a manera de ese halo de misterio que deriva de una escalera inconclusa. Como si esperase que desde ese lugar emergiera la Malena a la que le canta Homero Manzi. El clima que envuelve a la imagen adquiere entonces la otra dimensión que posee, la percepción del sonido. Dado que las imágenes no afectan solamente al sentido de la vista, sino también a los oídos y al olfato; las sensaciones experimentadas por estos son causadas asimismo por irradiaciones de las imágenes.

Recuerdo que el lugar está en la intersección de la calle Columna Pretes y la avenida Coronel Aureliano Buendía. Una esquina mítica donde suceden estas cosas y pueden pasar muchas más, en la medida que la fotografía circule entre distintos observadores, de los dos tipos, de los que transitaron por el lugar como de aquellos que jamás lo recorrieron. Sucesos congelados, en una especie de presente perpetuo, activarán otras lecturas, otras vivencias en las que la imagen no será necesariamente culpable. Es menester que entre en juego con distintas imaginaciones para encontrar nuevas voces. Esto sin contar que en el juego de lectura aquí propuesto se han tomado sólo unos pocos elementos de lo que contiene. Podríamos detenernos en esos niños que juegan en la banqueta; o ese otro señor que pone cara distraída mientras el perro unido a él por el cordel hace sus necesidades; o esos jóvenes que se soban con fruición, besándose con idéntico ánimo; o la viejita que los observa con ganas de haber nacido en época más reciente; o esos licenciados que grillan la mejor forma de servir al pueblo al que representan; o esos 
ladronzuelos que permanecen atentos a la posibilidad del próximo atraco automovilístico, o aquellos otros; o los de más acá sin olvidar a los de más allá, como aquel que se ha guarecido en un pórtico del inclemente mientras descansa junto a sus timbales con los que obtiene algunas monedas. Sin salir de los propios personajes y sus actitudes podemos continuar con la lectura de sus indumentarias, el calzado, la vestimenta, tanto por calidad como por actualidad y formas de uso.

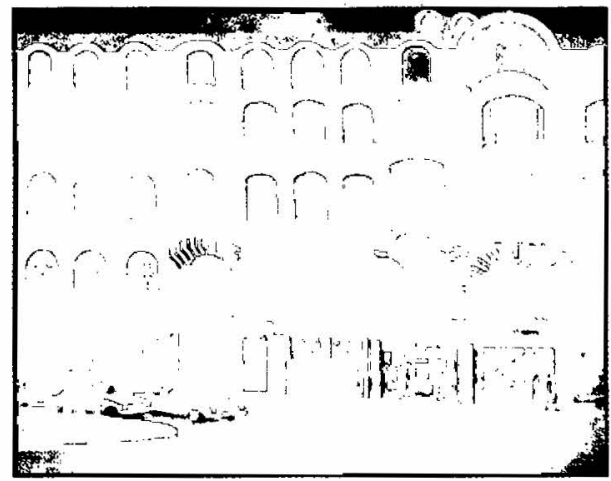

¿Y los edificios? Al fondo se divisa una torre con su innegable sentido fálico, su intención de llegar al cielo y obtener la supremacía sobre su entorno. $\mathrm{O}$ el propio símbolo del cielo en esa cúpula, que parece un bosquejo en el paisaje diluido. $O$, más acá, el misterio que los balcones representan. $\mathrm{O}$ los arcos que se dibujan en una fachada, contrapuestos a un muro ciego que declara con la solidez de su presencia la contundencia de la intimidad que preserva. La gran cantidad de signos que la arquitectura propone: soporte, sostén, cerramiento, apertura, repetición, ritmo, dirección, movimiento, cavidad, coherencia, ornamento, jerarquía. O la asociación con elementos geométricos: el punto, la línea, el cubo, la esfera, la pirámide.

El color es otra dimensión a considerar cuando se realiza el análisis de una imagen. Tanto el que corresponde a lo edificado, o al de las señales de tránsito, como el que deambula en las personas que lo portan en su indumentaria y los vehículos diversos que circulan por la zona. Estos, asimismo, aportan una valiosa información sobre época, poder adquisitivo y preferencias estéticas, no con un sentido concluyente, porque necesitaríamos mayor información gráfica y 
conocimiento sociológico para intentarlo. Los elementos de lectura son variados y afecta a diversos niveles, cuyo intento por desagregarlos reconoce distintas paternidades, la intención aquí es hacer un barrido que entienda a las posibles angulaciones ${ }^{5}$ para realizarlo, tomando referencias que van más allá de la propia imagen. A su vez trata de entender que toda representación está cargada de cierto grado de significación. Dependerá de la intencionalidad del autor para que tal circunstancia alcance mayor profundidad, tal el caso que nos ocupa. Sin embargo, la más simple imagen turística tendrá una carga significante que se potenciará en la medida que la misma sea contextualizada.

Al identificar el lugar por la intersección de sus calles, recurro a otro elemento de indagación. Un plano de la ciudad permite observar, desde otro ángulo, ese rincón, convertido ahora en un conjunto de líneas con marcas en diversas direcciones. Una cuadrícula que se

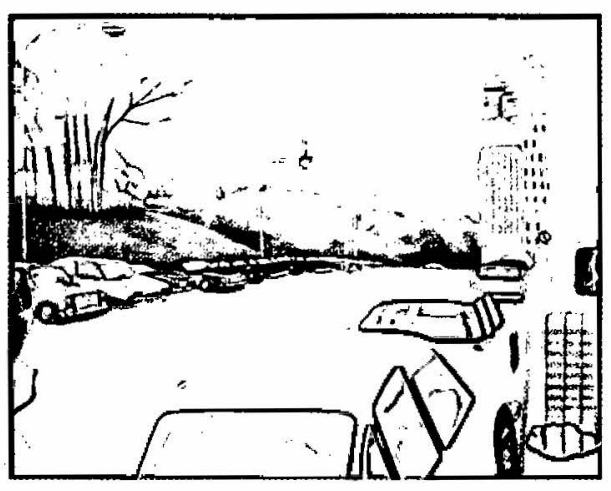
altera por la presión de otras formas precisas, círculos, trapecios, trapezoides, rectángulos y diversas figuras geométricas con las que el capricho y el progreso fueron agrediendo a la traza colonial (En lugar de tu bar me encontré una sucursal del banco hispanoamericano, dice Joaquín Sabina en $Y$ nos dieron las diez). En este plano, se pueden localizar mejor los elementos que abarca el conocimiento. Explicar donde se ubican las diferencias sociales que la foto no muestra o el callejón oculto. Esta individualización permite diseñar un tránsito hacia la zona, si se desea tomar contacto con la imagen corporeizada en su sitio original. Prever el recorrido mediante la información sobre líneas

5. Sabemos 10 que hay de desconcertante en la proximidad de los extremos o, sencillamente, en la cercania sübita de cosas sin relación; ya la enumeración que las hace entrechocar posee por si mismo un poder de encantamiento. (Foucault, 1998, p. 2). 
de autobuses o trenes subterráneos, cuadras que se tendría que cubrir caminando, calcular tiempos de recorrido para llegar a la hora señalada por el autor y, sí la obsesividad nos es permitida, consultar el estado del tiempo para encontrar un día con posible llovizna. La representación esquemática que el plano de la ciudad propone se convierte en otra imagen, con rasgos fundamentalmente conceptuales.

Esta esquematización que el mapa formula puede alcanzar una dimensión distinta si recurrimos a un complemento: la fotografía aérea. Tenemos allí un acercamiento vivencial que nos aproxima a una situación manifiesta y complementaria. Desde los valores simbólicos: el techo representación de lo femenino, principio protector. Y si bien en nuestro caso no se llega al extremo de algunos pueblos que decoran los tejados con tesoros y trofeos de caza para aumentar su fuerza protectora (Bruce-Mitford, 1997, p. 95), si podemos ver que es lugar de almacenamiento de objetos diversos que, fuera de su función de bodega, aparentemente práctica, pueden cumplir idéntico fin. Es posible leer también las características del asentamiento ${ }^{6}$, tanto por el material empleado como por aquellas terrazas dedicadas al esparcimiento, por ser solaz de sus residentes. También nos es dado mirar, curiosear, en la vida de los que allí habitan al observar sus patios, fondos y jardines.

Al mirar el sitio desde un punto de vista elevado, podemos continuar, por sucesivas ampliaciones de imagen, lo que no implica necesariamente la expresión gráfica, hasta el cosmos.

Después de esta larga disquisición sobre las potenciales de lectura de una imagen de ciudad, ella regresa a la visión de la propia fotografía para analizar una magnitud que parecía haber pasado desapercibida, aunque estuvo implícita en todo el discurso: la dimensión estética. Los valores formales, que la obra posee en amplitud. El tratamiento del color, el sentido del tono; los elementos compositivos, desde el encuadre, direcciones, equilibrio y pesos. La fuerza expresiva en el uso de la luz y los contrastes. El juego de texturas y la percepción del movimiento. La sensibilidad de su autor, en suma.

6. Las expresiones 'leer una casa', 'leer una habitación', tienen sentido, puesto que habitación y casa son diagramas de psicologia que guian a los escritores y a los poétas en el análisis de la intimidad (Bachelard, 1975, p. 70). 
Fue una imagen de una calle de ciudad, fue una parte de una imagen. En ese mismo sitio se pueden obtener diversas imágenes cambiando el ángulo o la hora del registro. Idéntico proceso se puede realizar en un sitio contiguo y en el que le sigue y el de más allá7. Ni tan siquiera es necesario registrarla, la ciudad provee de suyo innumeras imágenes. Es, por excelencia, un territorio de las imágenes.

La imagen juega un papel siempre importante en la práctica teatral contemporánea, pues se ha erigido en noción que se opone a las de texto, fábula o acción. El teatro habiendo reconquistado completamente su naturaleza visual de representación, llega incluso a invocar una sucesiŏn de imágenes escénicas y a tratar los materiales linguiísticos y actanciales como imágénes o cuadros (Pavis, 1996, p. 268).

\section{El escenario}

La ciudad es el gran pizarrón donde se escribe la historia. Su lectura, aunque evidente, no siempre es fácil por los signos contradictorios que presenta. Residencia por soberanía de la comunicación con el mundo, tal es el testimonio de cables y antenas, donde febriles transitan palabras e imágenes. La ciudad es un lugar de acontecimientos, reales y figurados, cotidianos y simbólicos. Es un sitio privilegiado de la memoria y su ejercicio. Es la plaza donde lidiar con los efectos inevitables del tiempo. Con enclaves de fealdad en ciertos entornos de rasgos estéticos avanzados. Enormes discordancias temporales, en el estilo, en lo artístico y en su. funcionalidad. Ámbitos que condicionan la obra aislada, enalteciéndola en su valoración o realzando su depreciación. Convivencia, no siempre armónica, de lugares públicos con sitios privados. Incidencia de ciertas edificaciones que alteran el desarrollo de la vida urbana, tales como fábricas o estadios deportivos, instalados en un entramado que no les corresponde. El hipódromo y el lugar para la muerte, verdadera ciudad

7. El mundo objetivo resulta dividido en dos esferas: una visible y la otra invisible, y desde el momento en que la cámara enfoca algo, inmediatamente surge la cuestión de saber no sólo que está viendo, sino también qué no existe para ella. (Lotman, 1979, p. 35). 
dentro de la ciudad. Los edificios en altura en desaforada competencia, verdaderas cajas de cristal, calentando la ciudad con sus reflejos.

\section{La escenografía}

Una espacialidad donde transcurre el acaecer humano. Lugar de expresión del diario acontecer que en su monotonía muestra lo diverso de los instantes que van cambiando. La suciedad, el humo, el calor, la congestión, el caos. El sentido frenético de lugares céntricos manifiesta su contraste con la bonhomía del barrio. La ciudad como territorio de caza, lugar anónimo y de riesgo. Las mil caras que se van modificando conforme avanza el tiempo, para repetir día tras día ese siempre renovado rito. La calle como ámbito supremo para el desarrollo de la vida y su actual contrapartida y competencia en el centro comercial que torna más anodina la experiencia. Los elementos móviles de una ciudad, en especial las personas, son tan importantes como las partes fijas. Las inscripciones en los muros, los graffitis como expresión conceptual y estética y su impronta actual con la modificación radical de sus códigos, cada vez más cerrados, en los que participan grupos humanos específicos. Los diversos elementos de comunicación gráfica, con sus anuncios inmóviles o animados, desde el espectacular al cartel y desde las señales de tránsito a las bandas peatonales.

\section{Los actores}

La ciudad, el hecho urbano, las edificaciones, las calles, comparten el concepto de imagen, imagen ambiental, tanto en las ideas de identidad, como en las de estructura y significado (Lynch, 1999, p. 17): identificación de un objeto, su distinción con respecto a otras cosas, su reconocimiento como entidad separable; la relación espacial con otros objetos y con el propio observador genera el sentido de estructura y de ellos se deriva el tercero, esa imagen debe tener cierto significado, intelectual, práctico o emotivo. El desarrollo de la 
imagen constituye un proceso bilateral entre observador y observado, es posible fortalecer la imagen mediante artificios simbólicos, utilizando intermediarios plásticos o con la manipulación de la imagen por medios electrónicos; o mediante la reeducación de quien lo percibe, $o$ bien remodelando el entorno. Una ciudad que pudiera aprehenderse con el tiempo como una gran continuidad, con sus muchas partes diferenciadas pero nítidamente vinculadas entre sí. Una imagen ambiental eficaz confiere a su poseedor una fuerte sensación de seguridad emotiva. Donde sus rasgos más determinados y preeminentes: espacialidades abiertas, la vegetación, el sentido del movimiento en las grandes vías, los contrastes visuales, resulte ser la expresión de particular importancia en el paisaje urbano de que se trate.

\section{La puesta en escena}

La espacialidad de la ciudad latinoamericana, diversa a los antecedentes que permitieron su surgimiento, singular en su caos vital, expresión de la luz del paisaje que la contiene. Ciudades mediterráneas, ciudades puertos, de montaña o del llano, de fundación reciente o de gran abolengo histórico.

\section{La representación}

La ciudad en el día y en la noche, el centro y la periferia, la calle y el parque, el invierno y el verano, el sol y la lluvia, el conjunto edilicio y el detalle, el orden arquitectónico y la fachada singular, el movimiento citadino y el silencio de los ventanales, el tráfago automovilístico de las avenidas y las zonas de reposo, la presencia del muro con sus ornamentos y los cristales que marcan su ausencia, los elementos de identificación y de redundancia, el interior público, como el bar, el restaurant, y el interior privado, como la casa, las diversas ciudades que viven en una misma ciudad, los objetos que constituyen el mobiliario urbano, las construcciones que congelan el tiempo y los edificios actuales que niegan toda singularidad a las ciudades, ubicándolas en una tierra de nadie que las hace similares a 
las de otra parte, a las de cualquier parte, verdadera transnacionalización de la arquitectura y el urbanis-mo. Los componentes estandarizados, tan típicos de las construcciones modernas, como un reflejo de los métodos, de la práctica técnica y de los principios estéticos del presente. El diseño urbano, siendo un hecho espacial, lo es también temporal. La ciudad cambia constantemente, sin un patrón establecido, alejada de toda métrica musical, es sólo pautada por la organización de sus calles, la estructura de sus cuadras

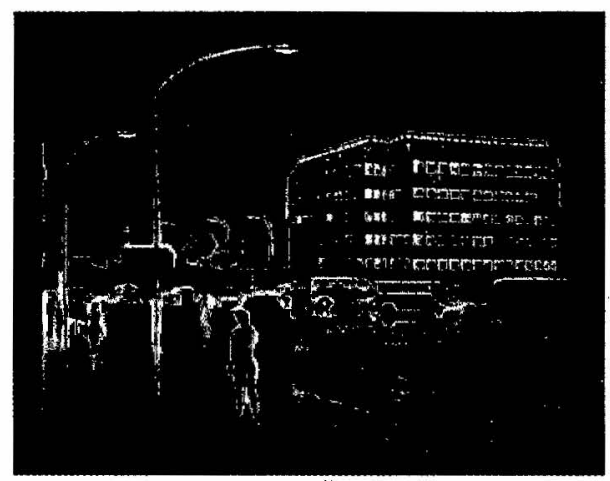

y ciertos códigos municipales, hechos que muchas veces resultan arrasados a nombre del sacrosanto progreso. La renovación urbana por criterios de funcionalidad, generalmente de fascinación por el cambio y, sobre todo, de modernidad, enmascarando el mercantilismo. Provocan el rompimiento abrupto del entorno modificando la trama y alterando las estructuras.

\section{Si yo imagino}

Si yo imagino que tú imaginas no quiere decir que los dos estemos imaginando lo mismo. Si una imagen gráfica nos sirve de intermediaria, podremos acercarnos tantito. Si a esa imagen la produce uno de nosotros, mejor. Seguro que no alcanzaremos el punto final de la convergencia. Nos puede servir de consuelo que jamás Van Gogh pudo pintar ese amarillo que buscó durante toda su vida. 


\section{Bibliografía}

ABBAGNANO, Nicola. 1999. Diccionario de Filosofía. México: Fondo de Cultura Económica.

ALEXANDER, Christofer.1976. Urbanismo y participación. Barcelona: Gustavo Gili.

ARNHEIM, Rudolf. 1962. Arte y Percepción visual. Buenos Aires: Eudeba.

BACHELARD, Gaston. 1975. La poética del espacio. México: Fondo de Cultura Económica.

BELJON, J. J. 1993. Gramática del arte. Madrid: Celeste ediciones. BENEVOLO, Leonardo.1979. Historia del urbanismo moderno. Madrid: Editorial Blume.

BERGMAN, Ingmar.1992. Imágenes. Barcelona: Tusquets Editores.

BRUCE-MITFORD, Miranda. 1997. Signos y símbolos. Buenos Aires: El Ateneo.

CARRIZO, Antonio. 1983. Borges el memorioso. México: Fondo de Cultura Económica.

CASTELLS, Manuel. 1978. La cuestión urbana. México: Siglo XXI.

DORFLES, Gillo. 1963. El devenir de las artes. México: Fondo de Cultura Económica.

FERRATER MORA, José. 1998. Diccionario de Filosofía Abreviado. México: Editorial Hermes.

FOUCAULT, Michel. 1998. Las palabras y las cosas. México: Siglo XXI.

GARCÍA CANCLINI, Néstor (coord.).1998. Cultura y Comunicación en la Ciudad de México, Primera parte, Modernidad y multiculturalidad: la ciudad de México a fin de siglo. México: UAM y Grijalbo.

1998. Cultura y Comunicación en la Ciudad de México, Segunda parte, La ciudad y los ciudadanos imaginados por los medios. México: UAM y Grijalbo. 
GIDIEON, Sigfrido. 1968. Espacio, tiempo y arquitectura. Barcelona: Ediciones McGraw Hill.

GREIMAS, A. J.; COURTÉS, J. 1991. Semiótica. Madrid: Editorial Gredos.

LEFEBVRE, Henri. 1975.El derecho a la ciudad. Barcelona: Ediciones Península.

1975. La revolución urbana. Madrid.

LYNCH, Kevin. 1999. La imagen de la ciudad. Barcelona: Gustavo Gili.

LOTMAN, Yuri M. 1979. Estética y Semiótica del Cine. Barcelona: Editorial Gustavo Gilli.

MÜLLER-BROCKMANN, Josef. 1988. Historia de la comunicación visual. Barcelona: Gustavo Gili.

MUMFORD, Lewis. 1979. La ciudad en la historia. Buenos Aires: Infinito.

PAVIS, Patrice.1996. Diccionario del teatro, Dramaturgia, estética, semiología. Barcelona: Paidos Comunicación.

RODRÍGUEZ VIQUEIRA, Manuel; IBAÑEZ, Pedro Manuel (coord.). 1992. Las ciudades del Encuentro. México: Noriega Editores.

ROPARS WUILLEUMIER, Marie Claire. 1971. Lecturas de cine. Madrid: Editorial Fundamentos.

SONTAG, Susan. 1996. Contra la interpretación. Madrid: Alfaguara.

TOPALOV, Christian. 1979. La urbanización capitalista. Edicol.

UNIKEL, Luis. 1976. El desarrollo urbano de México. El Colegio de México.

VÁZQUEZ RIAL, Horacio. 1988. Las ciudades, Buenos Aires. Barcelona: Ediciones Destino. 